\title{
JOINTS OF STEEL-BRASS ONE-SIDE WELDED BY EXPLOSIVE METHOD
}

\begin{abstract}
H. DYJA
Częstochowa University, Armii Krajowej 19, 42-200 Częstochowa, Poland

A. Maranda and J. Nowaczewski

Military University of Technology, Kaliskiego 2, 01-489 Warszawa, Poland

In this paper the results of investigation of the BW08 steel and M80 brass joints are presented. These joints were formed in three-layer billets (brass-steel-brass) during two-stage and one-side explosive welding. The investigations included microhardness and metallographic examination as well as determination of the superficial distribution of elements. On the basis of the results obtained it can be stated that the process of steel-brass joining runs in a high complicated manner through a plastic deformation and adhesion phenomena.
\end{abstract}

PACS numbers: $81.20 . \mathrm{Gx}$

\section{Introduction}

From many types of multi-layer materials the cold-rolled trips destined for press forming are those widely used in a material technology. The core of such trips, made of low-carbon steel was covered two-sided by high-cooper brass. The trips can be obtained from multi-layer billets welded initially by the explosive method [1]. In this paper results of the investigations of BW08 steel and M80 brass joints formed in three-layer billets (brass-steel-brass) during the one-sided and two-stage explosive welding are presented. The results as the complement to investigations are presented in papers [2-4].

\section{Experimental}

The billets were obtained by explosive welding of the BW08 steel plate $(100 \times 300 \times 1200 \mathrm{~mm})$ with two brass plates $(10 \times 350 \times 1300 \mathrm{~mm})$ placed in a parallel configuration. An amonal-type explosive of the density of $0.9 \mathrm{~g} / \mathrm{cm}^{3}$ and the detonation velocity of $1800 \mathrm{~m} / \mathrm{s}$ was used in the welding process. The samples destined to investigation were cut out from the central part of steel-brass bimetal. They were grinded using abrasive papers of $120,280,400$, and 800 grains and polished by means of diamond and aluminium oxide pastes. The samples prepared 


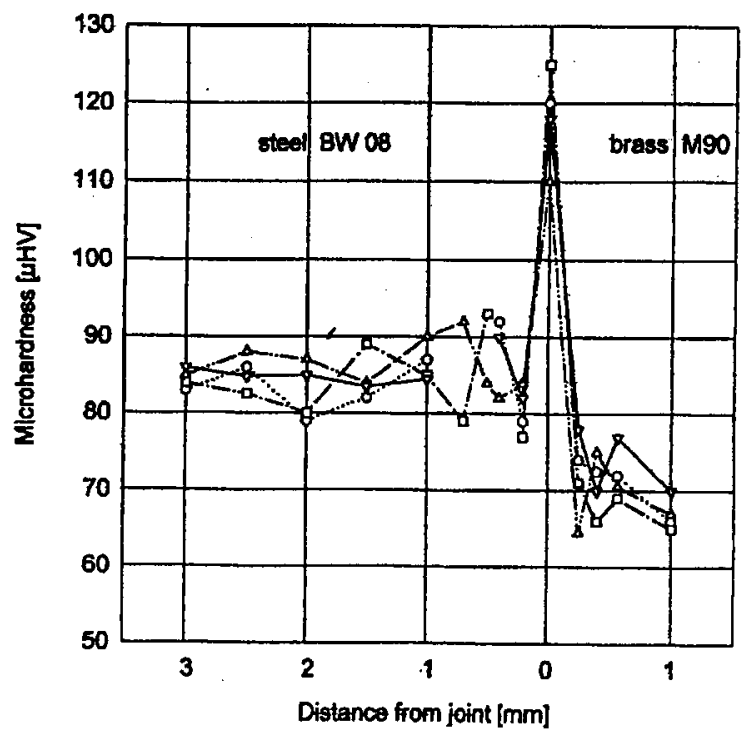

Fig. 1. Distribution of hardness in the jointed region. $\triangle, O, \square, \nabla$ describe measurement results for four lines perpendicular to the joint.
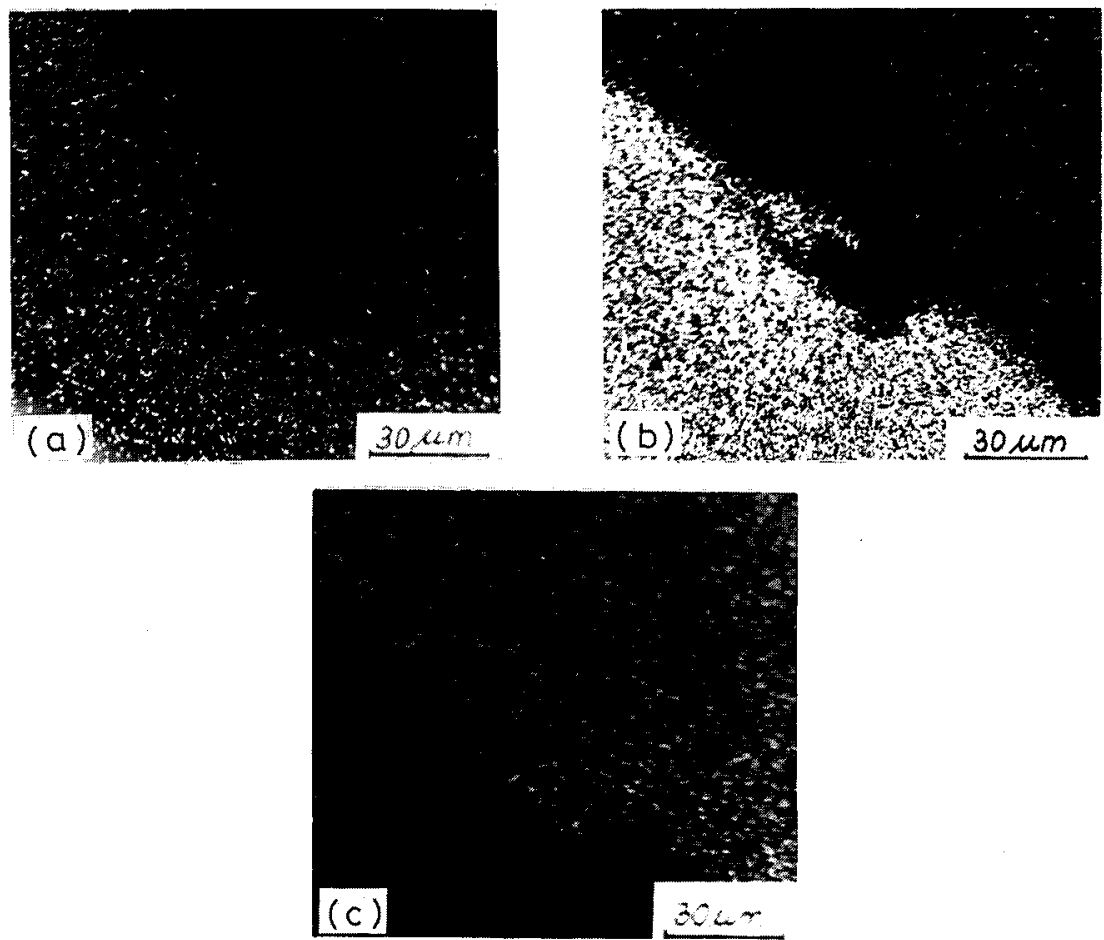

Fig. 2. Surface distribution of: (a) $\mathrm{Fe},(\mathrm{b}) \mathrm{Cu}$, (c) $\mathrm{Zn}$ in the joint. 

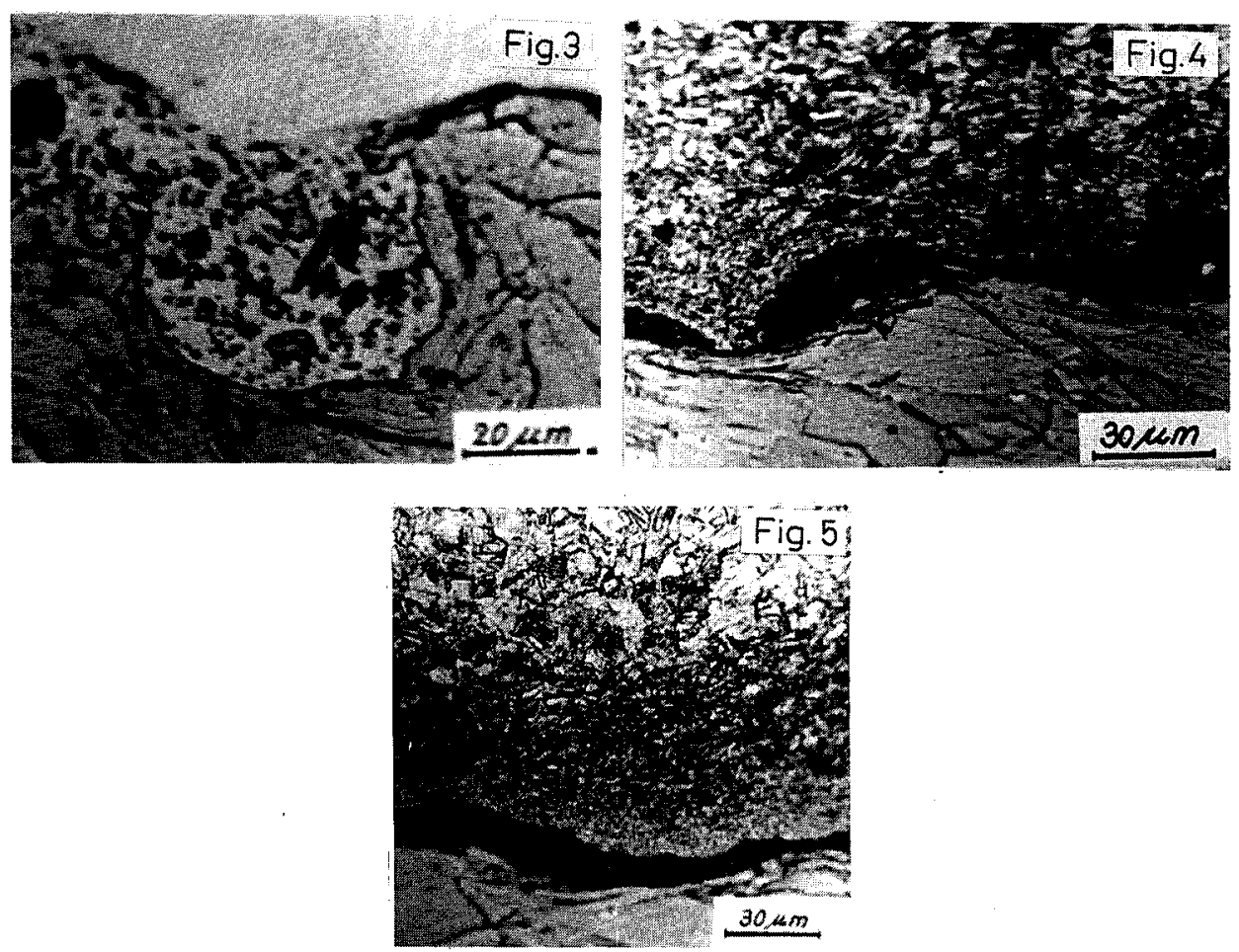

Fig. 3. Joint with whirls.

Fig. 4. Intermediate layer of the joint.

Fig. 5. Microstructure of brass near the joint.

in this way were investigated using a PMT-3-type microhardness tester supported with the $100 \mathrm{G}$ load applied along a line perpendicular to the joint. The results of microhardness measurements are presented in Fig. 1. In order to answer a question whether a diffusion process takes place at the phase boundary, the surface distribution of elements ( $\mathrm{Fe}, \mathrm{Cu}, \mathrm{Zn}$ ) was established by means of scanning electron technics (Fig. 2).

The metallographic investigations were accomplished using a Reichert-type microscope. To study the structure of metals joined, the specimen surface was etched by the MS reagent comprising $30 \mathrm{~cm}^{3} \mathrm{HCl}, 10 \mathrm{~g} \mathrm{FeCl}_{3}$, and $120 \mathrm{~cm}^{3}$ ethanol. Microstructures of metal formed during explosive welding are shown in Figs. 3-5. Metallographic investigations were also made using a Philips EM3016 transmission electron microscope, applying carbon replicas method prepared in a traditional way [5]. The chosen structures are presented in Figs. 6-8.

\section{Conclusions}

1. Brass and steel are strengthened in a significant degree during explosive welding, especially in surroundings of the joint line. A sharp increase in microhardness was observed in the joint. Elongated grains with numerous deformed 

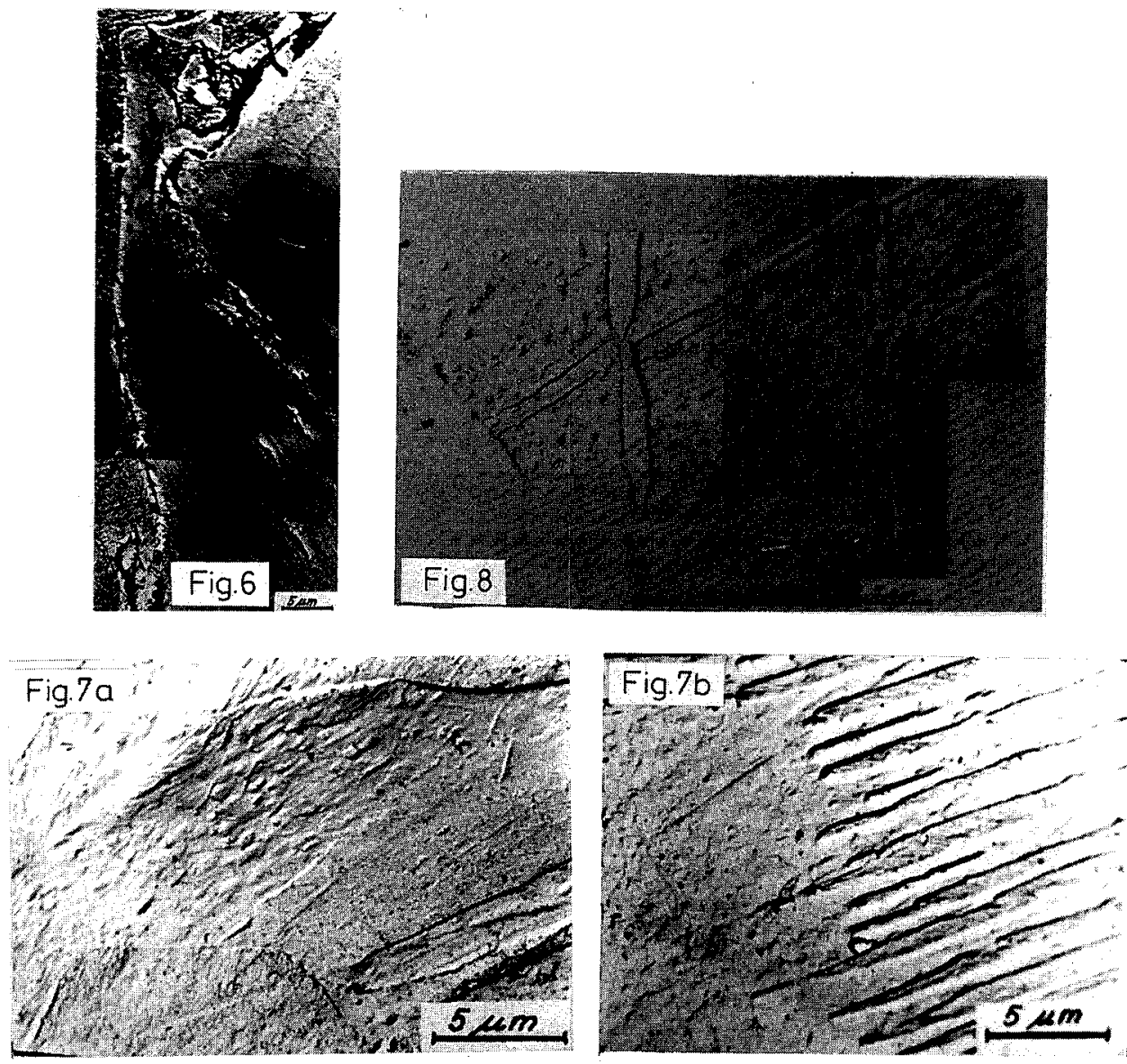

Fig. 6. Whirls in the wavy joint (carbon replica).

Fig. 7. Deformed grains of ferrite (a) and deformation twins in steel (b) (carbon replica).

Fig. 8. Needle structure of steel near the joint (carbon replica).

twins were visibled in the microstructure of steel as well as high dislocation density was stated in this region. In brass a great refinement of microstructure was established, in the joint which has been effected by a rapid solidification during explosive welding.

2. The connection brass-steel obtained by the explosive method has a miscellaneous nature. There are sections of planar joints and those of wavy joints with a small amplitude of wave. At intervals, there are wavy joints with whirls.

3. An intermediate layer is observed in some short sections of the joint. This layer is formed while solid and partially melted metals are being mixed due to the interaction of the displacing cumulative jet.

4. The process of steel-brass joining is realized not only by a plastic deformation however the adhesion phenomena may play an important role. 


\section{References}

[1] H. Dyja, A. Maranda, J. Nowaczewski, B. Zygmunt, Biul. WAT 37, 10, 75 (1988) (in Polish).

[2] N. . Berezina, V.M. Kudinov, Avtomat. Svarka 25, 2, 19 (1972).

[3] B. Wronka, Przegl. Spawalnictwa 38, 1, 8 (1986) (in Polish).

[4] S.K. Bauerjee, B. Crossland, Metal. Const. Brit. Weld. J. 3, 7, 268 (1971).

[5] W. Walczak, Przegl. Spawalnictwa 21, 4, 97 (1969) (in Polish). 